\title{
O PAPEL DO DIREITO À NÃO DISCRIMINAÇÃO NO ENFRENTAMENTO DA LÓGICA COLONIAL
}

\section{THE ROLE OF THE RIGHT TO NON-DISCRIMINATION WHILE FACING COLONIAL LOGIC}

\author{
${ }^{1}$ Paulo Víctor Schroeder
}

\section{RESUMO}

O conceito de "ser humano" que toma como ponto de partida a concepção de sujeito advinda do imaginário moderno mostrou-se excludente. O raciocínio colonial resulta em um processo de vulnerabilização de sujeitos com base em características específicas como raça, gênero, etnia e sexualidade. O Direito Internacional dos Direitos Humanos responde à demanda de sujeitos subalternizados por meio da face antissubordinação do direito à não-discriminação, reprovando tratamentos que criem ou perpetuem situações de opressão e materializando estratégias capazes de enfrentar a concepção individualista do direito à igualdade.

Palavras-chave: Direitos humanos, Colonialidade, Vulnerabilidade, Não discriminação

\begin{abstract}
The concept of human being that takes as starting point the conception of the subject arisen from the modern imagination has proven itself exclusionary. The colonial reasoning results in a vulnerabilization process of subjects based on specific characteristics such as race, gender, ethnicity and sexuality. The International Human Rights Law responds to the demand of subalternized subjects through the no subordination face of the right to non-discrimination, reproving treatments that create or perpetuate situations of oppression, and materializing strategies to face the individualist conception of the right to equality.
\end{abstract}

Keywords: Human rights, Coloniality, Vulnerability, Non- discrimination

\footnotetext{
${ }^{1}$ Mestrando em Direito Público pela Universidade do Vale do Rio dos Sinos - Unisinos, São Leopoldo, Rio Grande do Sul, (Brasil). Membro do Núcleo de Direitos Humanos /Unisinos. Bolsista CAPES/PROEX. E-mail: tutortreinamento@gmail.com
} 


\section{INTRODUÇÃO}

Com a colonização do continente americano, a principal forma de legitimar as relações de dominação provindas da conquista ocorreu por meio da naturalização de uma estratégia específica: a associação entre as características identitárias dos povos colonizados e posições subalternas na organização social que se formara. Trata-se de um projeto que possibilitou a acumulação de capital no Ocidente com a exploração dos povos originários da América e da África. Esse processo resultou na posição privilegiada atingida pelo Ocidente na nova organização mundial globalizada, que começava a se desenvolver com o advento das Grandes Navegações, fundamentada na criação da ideia de raça, e que se perpetua ainda hoje na contemporaneidade por meio do controle ocidental de toda produção epistemológica mundial.

Populações colonizadas, tratadas como "menos racionais" que os ocidentais e "mais aptas" à elaboração de trabalhos manuais, pois "menos propensas" à intelectualidade, são submetidas a processos de vulnerabilização, nos quais seus direitos básicos são violados das mais diversas formas. Esses sujeitos, expostos a verticalização da lógica específica provinda do colonialismo, a colonialidade, precisam incessantemente esforçar-se para que sejam reconhecidos como plenamente humanos. Nesse panorama, o Direito Internacional dos Direitos Humanos vem se instrumentalizando no sentido de possibilitar uma proteção adequada àqueles que possuem seus direitos violados apenas por possuírem determinadas características, o que pode ser percebido através do reconhecimento do direito à não discriminação, um desdobramento do direito à igualdade.

Este trabalho apresenta de forma inédita o cerne do trabalho de conclusão de curso de graduação desenvolvido no âmbito do Núcleo de Direitos Humanos/Unisinos e vinculado à linha de pesquisa "Sociedade, Novos Direitos, e Transnacionalização" do "Programa de Pós Graduação em Direito da Unisinos", mais especificamente ao projeto "Direito das Minorias e Grupos Vulneráveis: uma Análise do Discurso de Fundamentação nas Decisões do STF”.

Por meio da pesquisa exploratória, a problematização é feita utilizando-se o procedimento técnico da pesquisa bibliográfica transdisciplinar, utilizando livros e artigos de natureza jusfilosófica, histórica e antropológica para identificar de que forma o direito à nãodiscriminação responde à demanda do direito internacional dos direitos humanos pela proteção dos direitos de sujeitos que foram sistematicamente excluídos do campo semântico de "humano racional", constituindo grupos em situação de vulnerabilidade em decorrência da atuação da colonialidade na formulação da ideia de sujeito racional moderno. Dessa forma, o presente artigo abrangerá a relação entre a lógica colonial e a subalternização de determinados 
sujeitos para apresentar a resposta do direito internacional dos direitos humanos à violação de direitos humanos de sujeitos e grupos vulneráveis através do direito à não discriminação, problematizando as suas perspectivas antidiferenciação e antissubordinação.

\section{O DIREITO À NÃO DISCRIMINAÇÃO COMO O APORTE DO DIREITO INTERNACIONAL DOS DIREITOS HUMANOS À LÓGICA COLONIAL}

A consolidação de discursos naturalizados que vem resultando em práticas discriminatórias desde o advento da modernidade encontra a sua expressão material na violação dos direitos humanos de minorias desempoderadas, demonstrando a relação imediata entre a desumanização de determinados sujeitos e a negação de acesso a garantias básicas preconizadas pelos direitos humanos (ADAMATTI; BRAGATO, 2014, p. 93). Os sujeitos inferiorizados pela lógica específica da modernidade, a colonialidade, são os mesmo que, ainda hoje (na contemporaneidade), precisam esforçar-se para adentrarem no campo semântico de "ser humano racional" para que possam reivindicar a sua consequência mais básica, o reconhecimento pleno dos direitos humanos.

Por isso, o Direito Internacional dos Direitos Humanos vem criando um sistema jurídico que contemple garantias àqueles cujos direitos são violados apenas em razão de possuírem determinadas características identitárias (ADAMATTI; BRAGATO, 2014, p. 93). Nesse panorama, o direito à não discriminação vem possibilitando a formulação de estratégias capazes de enfrentar os critérios produzidos pela modernidade e que, desde então, atuam agrupando os membros da espécie humana entre o privilégio e a intolerância.

\subsection{Direito à Igualdade e à Não-discriminação}

A história dos direitos humanos ao longo dos últimos três séculos revela um processo lento e extremamente dificultado de expansão do reconhecimento de sujeitos de direitos no sentido de se possibilitar o empoderamento progressivo de grupos invisibilizados (DONNELLY, 2001). Pessoas em situação privilegiada de domínio social são gradativamente expostas à percepção de que as diferenças de raça, propriedades, religião, cor, sexo, linguagem, opinião política, origem social e nacional não são cenários legítimos para a limitação de direitos básicos (DONNELLY, 2001).

Com a compreensão do direito à não discriminação, que expressa a ideia básica sobre a qual todo o sistema internacional de direitos humanos fora criada, "que todos os seres 
humanos, independentemente do seu status social ou de sua pertença a determinados grupos, devem ser titulares de um conjunto de direitos básicos" (MOECKLI, 2010, p. 193) (tradução nossa $)^{1}$, busca-se o reconhecimento material da irrelevância de características específicas para a aplicação de direitos através de uma série de ações afirmativas que compelem os estados ao abandono da submissão de seus cidadãos à paradigmas preconceituosos (DONNELLY, 2001, p. 548). Nas palavras de Anne F. Bayefsky

Nos últimos 45 anos, organismos internacionais têm se concentrado, de foram contínua, no desenvolvimento da promulgação do direito à igualdade. Esse processo vem ocorrendo em diversos contextos: em relações civis, políticas, econômicas, sociais e culturais; emprego, salário e educação; tortura, raça, gênero e infância (1990, p. 2). (Tradução nossa) ${ }^{2}$.

Todos os seres humanos possuem os mesmos direitos à liberdade de expressão, de aprendizado, de pensamento, de voto, de expressar suas opiniões, de desempenhar cargos, de autonomia sexual e de exercer a sua própria religião (SHELTON, 2010). Nesse aspecto, o Direito Internacional dos Direitos Humanos reconhece e protege a diversidade dos seres humanos quanto aos seus atributos, capacidades, metas e habilidades, no intuito de permitir que todas as pessoas possam exercer a sua autodeterminação de modo amplo, sem frustrar a autonomia dos demais participantes do corpo social (SHELTON, 2010, p. 262). Assim, a proteção à igualdade através do direito à não discriminação surge para garantir a integralidade física e moral de pessoas historicamente subalternizadas. Nas palavras de Dinah Shelton

\begin{abstract}
A igualdade e a proibição de discriminação estão implícitas nas garantias formuladas nos instrumentos dos direitos humanos, que garantem tais direitos a „todas as pessoas", a „todo o mundo "e, ou a „todos os seres humanos". Dessa forma, o direito de não padecer a discriminação e de gozar a igualdade no exercício dos direitos tem sido denominado como „direito mais fundamental": [...] o ponto de partida das demais liberdades" $(2010$, p. 262). (Tradução nossa) ${ }^{3}$.
\end{abstract}

Não são todas as distinções legitimadas pela lei que vão necessariamente de encontro à proteção internacional contra a discriminação, pois o que se busca evitar são as diferenciações

\footnotetext{
${ }^{1}$ No original: "that all human beings, regardless of their stauts or membership of a particular group are entitled to a set of rights".

${ }^{2}$ No original: continua, al desarrolloy la promulgación del derecho de igualdad. Esto ha ocurrido en diversos contextos: en relación con derechos civiles, políticos, económicos, sociales y culturales; en empleo, remuneraciones y educación; y en tortura, raza, sexo e infancia

3 No original: "Equality and non-discrimination are implied in the fact that human rights instruments guarantee rights to "all persons", "everyone", or "every human being". In fact, the right to be free from discrimination and to enjoy equality in the exercise of rights has been called "the most fundamental of the rights of man [...] the starting point of all other liberties".
} 
que tendem a gerar danos injustificáveis a determinados sujeitos (DONNELLY, 2001). Apesar do reconhecimento do direito à igualdade para todas as pessoas, grande parte dos direitos consagrados pelo Sistema Internacional de Proteção aos Direitos Humanos não estão realmente assegurados de igual forma para todos, tendo em vista que a própria lei estabelece fatores de discriminação legitimados e justos - como a utilização da idade para limitar o exercício do direito de voto (SHELTON, 2010). Bragato e Adamatti referem que

[...] é preciso atentar para o fato de que o conceito de discriminação exige, para sua configuração, que a ação tenha por propósito ou efeito anular ou prejudicar o reconhecimento, o gozo ou o exercício em pé de igualdade de direitos humanos e liberdades fundamentais. Quando não se verifica esse télos, em princípio a distinção é legítima. (ADAMATTI; BRAGATO, 2014, p. 97).

Nesse cenário, o direito à não discriminação se apresenta como parte de uma justiça distributiva, que incorre na necessidade de se tratar de forma igual aqueles que estão em posição de igualdade e de forma desigual os que estão em situação desigual, tendo em vista que, conforme Dinah Shelton (2010, p. 262), "a consistência do tratamento pode falhar para garantir os objetivos mais amplos de igualdade, se aplicada por si só, sem levar em conta as diferenças e as semelhanças entre a população (tradução nossa) ) $^{4}$. Pretende-se, com isso, uma abordagem que combata todas as formas de "prejudicar indivíduos ou grupos por meio de distinções ilegítimas no gozo e exercício de direitos” (RIOS, 2008, p. 21).

\subsubsection{Desumanização e Discriminação}

O caráter histórico constitui-se como o elemento central do reconhecimento do direto à não discriminação. Aqueles para os quais o direito à igualdade é garantido explicitamente no Sistema Internacional de Proteção aos Direitos Humanos compõem grupos que foram metodicamente tratados como inaptos ao exercício do rol de direitos disponíveis ao abstrato sujeito de direitos moderno-ocidental. Nesse sentido, não são todas as práticas discriminatórias que violam diretamente o direito básico à não discriminação (DONNELLY, 2001). É por isso que aspectos que serviram para fundamentar a negação sistemática de direitos, como raça, cor, sexo, linguagem, religião, opinião política, origem nacional/social, posses e status de nascimento, possuem uma atenção especial do Direito Internacional dos

\footnotetext{
${ }^{4}$ No original: "As a result, consistency of treatment may fail to ensure the broader aims of equality, if applied on it owns without taking into account differences as well as similarities within the population.
} 
Direitos Humanos. Por exemplo, raça foi um fator que produziu/produz violações de direitos sistemáticas aos negros, motivo pelo qual diferenciações de trato baseadas na cor da pele tornam-se práticas inerentemente suspeitas (DONNELLY, 2001).

A vulnerabilização constitui-se, dessa maneira, como o elemento que precede a sujeição de determinados grupos de pessoas a práticas discriminatórias. A vulnerabilidade pode ser definida como "falta ou debilidade de poder econômico, cultural e/ou político de certos indivíduos ou grupos que obstaculiza a possibilidade de acesso igualitário aos bens e serviços necessários a uma vida digna" (ADAMATTI; BRAGATO, 2014, p. 98). Trata-se de um panorama que se constitui como a contrapartida estritamente conectada à existência dos grupos dominantes, caracterizados por sua situação de autoempoderamento social (ADAMATTI; BRAGATO, 2014). Conforme Adamatti e Bragato

Quando a modernidade europeia assentou o fundamento da dignidade na racionalidade humana e construiu o conceito de raça e racismo, produziu-se, historicamente, a construção de um padrão de humanidade encarnado na figura do indivíduo masculino, branco, proprietário, ocidental, heterossexual e cristão. Como padrão unitário, superior e cientificamente orientado de comportamento, a racionalidade tornou-se um atributo culturalmente centrado (ou etnocêntrico) e, portanto, ausente em diversos exemplares da espécie humana, como é o caso das mulheres, dos estrangeiros, dos colonizados, dos negros, dos deficientes e assim por diante (2014, p. 99).

Por consequência da utilização da racionalidade como um fator de exclusão, o processo de vulnerabilização de determinados sujeitos e grupos decorre de uma formação discursiva de desumanização (ADAMATTI; BRAGATO, 2014). As razões desse discurso atingem expressão material por meio de práticas discriminatórias, o que o Direito Internacional dos Direitos Humanos responde através da proibição da discriminação direita e indireta. Esses fatores de vulnerabilização, conforme Adamatti e Bragato

encontram-se expressamente consignados na normativa internacional e têm relação direta com os fatores que servem para definir a pertença de um indivíduo ou grupo ao padrão dominante. [...] A realidade dos grupos vulneráveis no Brasil reforça a noção de que determinadas categorias de pessoas encontram-se em situação de maior vulnerabilidade a justificar tratamentos diferenciados no sentido de potencializar o seu acesso aos direitos humanos" (2014, p. 100).

Dessa forma, busca-se uma equalização da distribuição de direitos na sociedade que não se materializa por meio da face meramente formal da igualdade, pois a compreensão sobre de o que é "um tratamento igualitário" exige uma interpretação complexa das relações 
de poder que produziram (e reproduzem) uma dinâmica colonial opressiva e dominante contra grupos que se encontram em posição histórica de desvantagem (ADAMATTI; BRAGATO, 2014 p. 92). Assim, a garantia plena dos direitos humanos passa necessariamente "pelo reconhecimento explícito do princípio da não discriminação como um mandamento de concretização dos direitos humanos" revelando-se uma possibilidade de enfrentamento à “compreensão liberal do conceito de igualdade de todos perante a lei" (ADAMATTI; BRAGATO, 2014, p. 102).

\subsubsection{Dimensão Direta e Indireta da Discriminação e as Perspectiva de Tratamento Igualitário a partir da Antidiferenciação e da Antissubordinação}

Conforme Roger Raupp Rios (2008, p. 32) “enquanto disciplina jurídica dogmática, o direito da antidiscriminação [...] se propõe a desenvolver respostas jurídicas frente à realidade da discriminação, a partir de conceitos jurídicos”. Assim faz-se necessária a identificação das possibilidades de manifestação da discriminação que se vinculam ao propósito com que a ação é praticada e ao efeito que produz (RIOS, 2008). A discriminação alcança não apenas práticas intencionais e conscientes (discriminação direta), mas também realidades permanentes produzidas através da manutenção de medidas aparentemente neutras, mas que apresentam um grande potencial discriminatório (discriminação indireta), que ocorre, por exemplo, quando leis e políticas públicas com aparente neutralidade acabam reforçando situações de vantagem e desvantagem já existentes na sociedade, relacionadas com fatores como raça e sexo, por exemplo (RIOS, 2008). Isso impõe a necessidade de diversas abordagens acerca do acesso igualitário aos direitos

Nesse sentido, Roger Raupp Rios identifica a existência de duas formas de se conceber a igualdade em um cenário de direitos: a perspectiva da antidiferenciação e da antissubordinação, que são óticas sob as quais se concebe o direito da antidiscriminação. A antidiferenciação reprova tratamentos que diferenciam os seres humanos independentemente do pretexto, "considerados critérios proibidos de diferenciação" (RIOS, 2008, p. 34). Nas suas palavras

A perspectiva antidiferenciação se preocupa com a neutralidade das medidas tomadas por indivíduos e instituições. Neste sentido, ela adota a perspectiva do agente da discriminação, buscando corrigir eventuais condutas discriminatórias. Primordialmente, ela orienta-se para a proteção de indivíduos vítimas de discriminação intencional. A perspectiva da antidiferenciação, portanto, é hostil à ideia de ações afirmativas em favor de 
certos grupos, considerando-as discriminatórias em relação a grupos não beneficiados. Ela refuta as instituição de qualquer medida específica, por considerá-la uma espécie uma espécie de "direito especial", verdadeiro privilégio incompatível com a igualdade de tratamento a que todos têm direito $(2008$, p. 34).

Essa compreensão apresenta-se como uma face radical da igualdade formal "enquanto proibição da instituição de qualquer distinção fundada nos critérios proibidos de diferenciação, gerando, por assim dizer, um „direito à indiferença” (RIOS, 2008, p. 34-35). A perspectiva antidiscriminação revela-se através da postulação de que a igualdade atue apenas em um campo negativo, o que gera dificuldades frente a necessidade de se lidar com as diferenças entre os seres humanos, pois, ao fundar-se em pressupostos supostamente "neutros" e "abstratos", essa concepção não esta apta para respaldar as diferenças "merecedoras de medidas específicas”. Conforme Roger Raupp Rios

[...] a relação da perspectiva antidiscriminação com o individualismo acaba restringindo o direito da anti-discriminação apenas aos casos de discriminação formal, perpetrada por um indivíduo com base em estereótipos e preconceitos que violam os critérios proibidos de diferenciação. Com efeito, nesta perspectiva não há como se imputar responsabilidade ou oferecer respostas diante da discriminação nãointencional, de cunho institucional (2008, p. 34-35).

Por outro lado, a concepção da antissubordinação desaprova qualquer tipo de tratamento que crie submissões entre seres humanos para o exercício de poder. Conforme Roger Raupp Rios, "Ela admite tratamentos diferenciados, desde que estes objetivem superar situações de discriminação, assim como considera discriminatórios tratamentos neutros que reforcem a subordinação de quem quer que seja" (RIOS, 2008, p. 36). Nesse aspecto, a antisubordinação tira o foco do princípio abstrato da aplicação da igualdade a todas as pessoas e passa a atuar diretamente no sentido de combater a vulnerabilidade de determinados grupo racializados. Ainda seugndo Roger Raupp Rios

Todos estes desdobramentos da perspectiva da anti-subordinação, decorrentes da atribuição de um conteúdo substancial ao direito da antidiscriminação, conduzem à concretização de uma das funções mais caras aos direitos fundamentais nas democracias contemporâneas, qual seja a proteção das minorias. Com efeito, a função protetiva de minorias é mais adequadamente desempenhada por um princípio da igualdade atento à situação dos grupos subordinados, na medida em que se atribui ao direito da antidiscriminação algo mais que um mero teste de racionalidade na eleição de critérios de diferenciação tendo em vista certas finalidades (2008, p. 41). 
Não discriminar passa não somente pela proibição da a ação de discriminar (como no caso das lutas antiapartheid), mas também pela promoção de ações que compensem as desvantagens históricas desses grupos no acesso a bens, como é o caso das ações afirmativas (DONNELLY, 2001). Por isso, a discriminação implica distinções em exclusões, preferências, limitações e restrições entre pessoas ou grupos desde que se identifique o nexo entre o grau de discrímen e o objetivo que se deseja atingir (SHELTON, 2010).

A igualdade, nesse sentido, deve ser garantida não só através da paridade de oportunidades, mas também com a garantia de resultados práticos iguais para os cidadãos (o que inerentemente gera consequências redistributiva). Ou seja: o objetivo da não discriminação é a igualdade de fato, pois atos discriminatórios possuem impactos distintos sobre os sujeitos subalternizados, fazendo com que as medidas meramente materiais não sejam adequadas padrões sistêmicos e complexos de desigualdade. Assim, conforme a autora Dinah Shelton

\footnotetext{
Além das modalidades de discriminação direta e indireta, poderia colocar-se o requisito de que, dentro do razoável, os Estados forneçam o necessário para acomodar as diferenças de entre os cidadãos mediante a modificação de leis e práticas com o intuito de permitir que as pessoas que reúnem determinados requisitos possam postular, ter acesso a funções necessárias e desfrutar de benefícios e privilégios que os demais membros da sociedade possuem acesso.(2010, p. 288). (Tradução nossa). ${ }^{5}$
}

O estudo da concepção anti-subordinação do direito à não discriminação surge como uma alternativa na busca pela eliminação de desigualdades em um campo formal, com a procura por estratégias que possam efetivamente atuar sob o cenário discriminatório e intolerante criado pela concepção moderno/colonial do sujeito de direito. Nesse sentido, o direito internacional dos direitos humanos está desempenhando um papel ativo para possibilitar o protagonismo de sujeitos historicamente inferiorizados, apresentando um novo discurso de direitos capaz de deslocar a concentração dos privilégios à disposição no globo das mãos de uma pequena parcela da população mundial.

\footnotetext{
${ }^{5}$ No original: "In addition to direct and indirect discrimination, there may be a requirement that states reasonably accommodate differences, by modifying laws and practices to make it possible for a qualified individual to apply, for perform the essential functions of, and enjoy the benefits and privileges available to others".
} 


\title{
2.2 Discriminação de Gênero e a Convenção Sobre a Eliminação de Todas as Formas de Discriminação Contra a Mulher
}

Catharine Mackinnon (2001) entende que a formulação teórica por trás da construção dos direitos humanos não engloba plenamente os direitos das mulheres, tendo em vista as formas específicas de agressão às quais são submetidas apenas pela pertença ao gênero feminino, para as quais o mero reconhecimento legal e formal do direito à igualdade não possui uma eficácia real. Nesse aspecto, movimentos feministas vêm lutando pela ideia de que as mulheres possuem direitos humanos fora desse cenário de violação, recusando-se a aceitar a posição societária que largamente reproduz a noção de que "ser mulher" significa estar submetida a agressões sistêmicas.

Nesse cenário de reivindicações, a proclamação do ano de 1975 como o Ano Internacional da Mulher, bem como a realização da primeira Conferência Mundial da Mulher, culminaram na aprovação, pelas Nações Unidas, da Convenção sobre a Eliminação de todas as formas de Discriminação contra a Mulher que, atualmente, conta com 189 ratificações (PIOVESAN, 2011). Conforme Alice Edwards

\begin{abstract}
À semelhança de outros tratados internacionais, a Convenção para Eliminação de Todas as Formas de Discriminação contra a Mulher, aplica-se a todas as mulheres, independentemente da sua nacionalidade, cidadania, ou qualquer outro status legal [...]. A convenção estabelece uma série de direitos civis, culturais, econômicos, políticos e sociais para as mulheres e abrange uma variedade de situações em que as mulheres enfrentam discriminações, como na política, na economia, na família, no trabalho, na educação e na saúde. Apesar de muitas críticas feministas à lei internacional de direitos humanos [...] muitos desses direitos são extremamente relevantes e podem ser efetivamente aplicados para mulheres e meninas desamparadas (2009, p. 8). (Tradução nossa) $)^{6}$.
\end{abstract}

O documento encontra congruência com a Convenção sobre a Eliminação de todas as formas de Discriminação Racial ao passo que prevê a possibilidade de se adotar medidas afirmativas com o intuito de viabilizar e acelerar o processo de luta pela igualdade, buscando a instrumentalização necessária para a aproximação a estratégias capazes de apresentar alternativas ao profundo cenário de opressões no qual a mulher está inserida (PIOVESAN,

${ }^{6}$ No original: "Like other human rights treaties, the CEDAW applies to all women regardless of their nationality, citizenship or other legal status [...]The CEDAW has been called the International Bill of Rights for Women. It sets out a range of civil, cultural, economic, political, and social rights for women and covers a variety of situations in which women face discrimination, including in politics, the economy, the family, employment, education and health. Despite the many feminist criticisms of international human rights law [...]many of these rights are relevant and can be applied effectively to displaced and stateless women and girls." 
2011). Dessa forma, os Estados, ao ratificarem a convenção, comprometem-se tanto com o reconhecimento formal da igualdade quanto com o seu aparato material. Conforme Andrew Byrnes

\begin{abstract}
A convenção em si mesma contém diferentes perspectivas sobre as causas de opressão contra as mulheres e as medidas necessárias para enfrentá-las. Ela impõe a obrigação de assegurar que as mulheres tenham uma igualdade formal perante a lei e reconhece que medidas temporárias de ação afirmativa são necessárias em muitos casos, para que as garantias de igualdade formal se transformem em realidade. Inúmeras previsões da Convenção também incorporam a preocupação de que os direitos reprodutivos das mulheres devem estar sob o controle delas próprias, cabendo ao Estado assegurar que as decisões das mulheres não sejam feitas sob coerção e não sejam a elas prejudiciais, no que se refere ao acesso às oportunidades sociais e econômicas. A convenção também reconhece que há abusos aos quais mulheres são submetidas, que necessitam ser eliminados (como estupro, assédio sexual, exploração sexual e outras formas de violência contra as mulheres (1989, p. 258-259).
\end{abstract}

Por meio da convenção, são estabelecidos mecanismos próprios de monitoramento que, a exemplo da Convenção sobre a Eliminação da Discriminação Racial, permitem a apreciação de relatórios enviados pelos Estados Partes, bem como o exame de petições individuais e a realização de investigação in $\operatorname{loco}^{7}$. Essas medidas possibilitam que o Comitê averigue violações contra os direitos das mulheres, graves e sistemáticos (PIOVESAN, 2011).

Sobre a grande adesão de Estados à Convenção, Flávia Piovesan (2011) observa uma situação paradoxal: trata-se do instrumento com maior formulação de reservas pelos Estados entre os tratados internacionais de direitos humanos, em função das diversas diferenças religiosas, culturais e legais entre os países. Em resposta, o Comitê sobre a Eliminação de todas as formas de Discriminação contra a Mulher, editou a Recomendação Geral $n^{\circ} 21$, que ressalta a necessidade de os Estados desencorajarem todas as ideias de desigualdade entre os sexos, para que se possa gradativamente eliminar as ressalvas que incidem sobre a Convenção (como a igualdade de direitos no casamento e relações familiares).

Em 2012, o Estado brasileiro compareceu ao comitê em razão da realização da $51^{\text {a }}$ Sessão, que ocorrera entre 13 de fevereiro e 2 de março. O relatório de recomendações, formulado após a realização da sessão, apontou aspectos positivos e negativos em relação ao progresso brasileiro pelo reconhecimento dos direitos da mulher. Quanto à temática da

${ }^{7} \mathrm{O}$ peticionamento individual, bem como a investigação in loco exigem a assinatura, pelos Estados, do Protocolo Facultativo à Convenção sobre a Eliminação de todas as formas de Discriminação contra a Mulher, que entrou em vigo em 22 de novembro de 2000. 
violência, o comitê ressaltou a importância acerca do pronunciamento do Supremo Tribunal Federal pela legalidade da Lei Marinha da Penha.

No entanto, ressaltou-se a resistência de vários setores do judiciário à aplicação da lei, do que foram feitas quatro recomendações principais: a promoção de treinamento sistemático a juízes, promotores e advogados que atuam com os direitos da mulher, para que se alinhem ao posicionamento do Supremo Tribunal Federal; o aprimoramento do sistema judicial para garantir que as mulheres (em especial aquelas em situação desfavorecida) tenham acesso efetivo à justiça; o aprimoramento do sistema de coleta de dados e de monitoramento do impacto da Lei Maria da Penha; e o fornecimento de recursos às entidades que participam do Plano Nacional de Combate à Violência contra as mulheres.

\section{POR UMA INTERPRETAÇÃO CONTEXTUALIZADA E DINÂMICA DO DIREITO À IGUALDADE E À NÃO DISCRIMINAÇÃO}

Catherine Mackinnon (1993) percebe que a abordagem material acerca da discriminação sexual é feita a partir de um paradigma masculino de humano, de forma que a masculinidade se torna a medida do direito de igualdade, em um aparato que atribui característica de neutralidade para a lei enquanto mantém a desigualdade dos sexos. Nas palavras da autora (1993, p. 167): “o gênero, elaborado e apoiado [...] pela lei, se mantém como divisão de poder. O Estado negativo percebe o gênero e as relações sexuais [...] com neutralidade" (tradução nossa). Essa acepção reflete a face meramente formal do direito à igualdade, que invisibliza as necessidades de medidas específicas, tratadas como supostos "privilégios", e não apresentando respostas eficientes às formas complexas de discriminação indireta e institucionalizada.

Conceber a legitimidade de tratamentos diferenciados a partir da acepção formal da igualdade, conceito com raízes modernas/coloniais, "é inviável por tratar-se de um elemento cerne do projeto moderno homogeneizante e excludente que concebeu a sociedade ideal como sendo aquela onde reina a unidade e não existem diferença” (ADAMATTI; BRAGATO, 2014, p. 106). Nas palavras de Daniel Moeckli

Muitas vezes a discriminação é a consequência de padrões profundamente enraizados de desvantagem e exclusão, que só podem ser enfrentados através de mudanças nas estruturas sociais e institucionais. Dessa forma, agora a lei internacional dos direitos humanos estabelece veementemente que não basta que determinado país possua legislação antidiscriminação. Em vez disso, existe a obrigação de que os estados promovam, garantam e assegurem a 
igualdade através de medidas proativas para a eliminação de padrões estruturais de desvantagem no sentido de possibilitar uma inclusão social mais ampla. Essa obrigação, muitas vezes referida como „ação positiva ${ }^{e e}$, tem o potencial de cobrir uma grande variedade de medidas legislativas, administrativas e políticas, que vão desde a total reestruturação das instituições até a prestação de „adaptações razoáveis ${ }^{\text {ee }}(2010$, p. 205).(Tradução nossa) ${ }^{8}$

A compreensão complexa e histórica dos direitos humanos exige um entendimento apurado acerca das realidades sociais, formadas por pluralidades e desigualdades, onde os seres humanos ocupam os espaços entre o infortúnio e o privilégio. Basta que se perceba a situação dos grupos vulneráveis no Brasil, cujo desequilíbrio em sua forma de tratamento demonstra o fato de que o gozo pleno de direitos humanos está atrelado a características como sexo, raça, cor e condição física ou mental (ADAMATI; BRAGATO, 2014). Nesse aspecto "o jurista precisa reconhecer a dinâmica das relações de poder e compreender de que forma o Direito, atento apenas à dimensão formal, reforça a opressão e a dominação de grupos e indivíduos historicamente em desvantagem" (ADAMATI; BRAGATO, 2014, p. 103).

\section{CONSIDERAÇÕES FINAIS}

Os sujeitos afetados pela experiência de vida de opressão própria da colonialidade do ser vivem em uma totalidade que naturalizou um estado de guerra no qual a exploração e o abuso são práticas impregnadas na vivência cotidiana. A modernidade possui um caráter paradoxal: por um lado exalta o seu ímpeto humanista e por outro legitima uma "não ética" de violação contra os corpos colonizados, em uma concepção que percebe esses sujeitos como não plenamente humanos. A pertença à humanidade é intrinsecamente interligada ao conceito de "razão", o que transparece na moderna formulação de "sujeito de direito". Apesar de o conceito de direitos humanos supostamente pressupor uma qualificação de humano como um conceito universal e que possa levar justiça a todas as populações do globo, na maior parte de sua utilização acaba deixando de fora a maioria dos seres humanos.

${ }^{8}$ No original: "In fact discrimination is often the consequence of deeply embedded patterns of disadvantage and exclusion that can only be addressed through changes to social and instutional structures. Accordingly, it is now well established in international human rights law that is not sufficient for states to have anti-discrimination legislation in place. Instead, they also have an obligation to promote, guarantee, and secure equality by taking proactive steps to eliminate structural patterns of disadvantage and to further social inclusion. This obligation, often referred to as the duty to take „positive action", may cover a huge variety of legislative, administrative, and policy measures, ranging from the restructuring of institutions to the provision of "reasonable accommodation". 
A visibilização da colonialidade do poder, a outra face dos princípios humanistas ocidentais, revela a fragilidade dos pressupostos sobre os quais o discurso dominante de direitos humanos fora construído. O "humano" para os quais se direcionam os direitos humanos é um produto da filosofia moderna, que remete "àqueles que são como eu”, permitindo a compreensão sobre de que forma, na história da humanidade, ocorreram (e continuam ocorrendo) as mais diversas violações aos direitos de grupos específicos: sob o pretexto da desumanização.

Compreender que as realidades sociais são formadas por grupos heterogêneos e desiguais, em que as pessoas estão organizadas entre aqueles que possuem voz para reivindicar seus direitos e aqueles cujas demandas são silenciadas, é necessário quando se pretende deslocar o gozo pleno de direitos humanos da pertença a agrupamentos que reúnem determinadas características como, por exemplo, sexo, raça e cor. Por meio da concepção antissubordinação do direito à não discriminação, surge uma alternativa na busca da eliminação de desigualdades não só no campo formal, mas também materializando estratégias capazes de efetivar o combate a um panorama social intolerante, que remete à concepção moderno/colonial individualista de "humano". O direito internacional dos direitos humanos está desempenhando um papel ativo para possibilitar o protagonismo de sujeitos historicamente inferiorizados, utilizando um discurso de direitos capaz de ressignificar o direito à igualdade.

Se a justiça possui o seu alcance delimitado por sua dimensão política, que estabelece quem está dentro e quem está fora do círculo daqueles que são titulares de uma justa distribuição e de reconhecimento recíproco, a luta comum a grupos de pessoas historicamente discriminadas pelo reconhecimento de sua humanidade tornam evidente o fato de que um tratamento igualitário em face da não discriminação requer um reconhecimento aprofundado acerca das relações de poder que produzem a opressão e a subjugação de grupos e de indivíduos historicamente vulnerabilizados.

A luta pela efetiva igualdade entre os seres humanos passa pelas diferenciações de tratamento frente à percepção crítica dos fatores que colocam indivíduos e grupos em situações de vantagem ou desvantagem na sociedade, com o intuito de possibilitar o confronto à compreensão liberal de igualdade que, por trás de uma suposta neutralidade, perpetua uma divisão de poder parcial. 


\section{REFERÊNCIAS}

BAYEFSKY, Anne F. The Principle of Equality or Non-Discrimination in International Law. Human Rights Law Journal. Tradução para o Espanhol de Centro de Derechos Humanos, Faculdad de Derecho, Universidad de Chile, v. 11, n. 1-2, p. 1-34, 1990.

BRAGATO, Fernanda; ADAMATTI, Bianka. Igualdade, não discriminação e direitos humanos: são legítimos os tratamentos diferenciados? Revista de informação legislativa, Brasília, v. 51, n. 204, p 91-108, out./dez.2014. p. 97.

DONNELLY, Jack. Non-Discrimination and Sexual Orientation: Making a Place for Sexual Minorities in the Global Human Rights Regime. In: HAYDEN, Patrick (Org.). The Philosophy of Human Rights. St. Paul: Paragon House, 2001.

EDWARDS, Alice. Displacement, Statelessness and Questions of Gender Equality under the Convention on the Elimination of All Forms of Discrimination against Women. Geneva: United Nations High Comissioner for Refugees: Division of International Protection Services. 2009

MACKINNON, Catharine. Hacia una teoria feminist del estado. Derecho y Humanidades, n. 3/4. p. 155-168, 1993.

MACKINNON, Catharine A. Rape, Genocide, and Women "es Human Rights. In: HAYDEN, Patrick (Org.). The Philosophy of Human Rights. St. Paul: Paragon House, 2001. p. 526542.

MOECKLI, Daniel; SHAH, Sangeeta. International Human Rights Law. Oxford: Oxford University Presso, 2010.

Nações Unidas. Concluding observations of the Committee on the Elimination of Discrimination agains Women - Brazil. Genebra, 2012. 
PIOVESAN, Flávia. Direitos Humanos e o Direito Constitucional Internacional. 12. Ed. São

Paulo: Saraiva, 2011.

RIOS, Roger Raupp. Direito da Antidiscriminação: discriminação direita, indireta e ações afirmativas. Porto Alegre: Livraria do Advogado Editora, 2008.

SHELTON, Dinah. Prohibited Discrimination in International Law. In: ZAIKOS, Nikos; CONSTANTINIDES, Aristotle (Org.). The Diversity of International Law: Essays in Honour of Professor Kalliopi Koufa 261. Boston: 2010. 